\title{
A "lógica da intervenção" e a questão da circulação As remoções de favelas como forma de gerir o espaço urbano no Rio de Janeiro dos Jogos Olímpicos
}

Alexandre Magalhães* https://orcid.org/0000-0002-9005-1244

Introdução

As remoções de favelas no Rio de Janeiro voltaram à agenda estatal nos últimos anos ${ }^{1}$. Em 2009, a prefeitura da cidade elaborou um ambicioso programa de remoções que, inicialmente, implicava a retirada completa ou parcial de 119 favelas do espaço urbano, representando, à época, aproximadamente 13 mil famílias. Tal programa se estruturou com base tanto nos esforços de atores institucionais e midiáticos para fazer emergir essa forma de intervenção sobre esses territórios, elaborando diferentes justificativas com vistas a legitimá-la e afastar qualquer crítica, como também contou com condições materiais específicas, especialmente com os aportes provenientes do programa do governo federal Minha Casa, Minha Vida².

* Universidade Federal do Rio Grande do Sul, Porto Alegre, Rio Grande do Sul, Brasil.

1. Diferentes autores se debruçaram, de perspectivas diversas, sobre esse processo. Destaco, entre outros, o trabalho de Guterres (2014) que comparou esse processo no Rio de Janeiro e em Porto Alegre; Fernandes (2013), que o observou sob a perspectiva das ocupações do Centro; Rolnik (2015), que tratou a questão com base em sua experiência como Relatora Especial da onU para o Direito à Moradia; de Naback (2015), que enfatiza a dimensão biopolítica desse processo e as possibilidades do "habitar"; Petti (2016), que reflete sobre o papel da casa nessa configuração; Azevedo e Falhauber (2015) que mapearam os fluxos desses deslocamentos na cidade; Freire e Silva (2016), que enfatizaram as estratégias de mobilização dos moradores contra a remoção; Davies (2017), que analisou as ameaças de remoção no contexto da produção de uma "região olímpica"; e por fim, do ponto de vista do planejamento urbano, destaco Tanaka, Sánchez, Oliveira, Monteiro (2016).

2. Em entrevista concedida aos pesquisadores Adauto Lucio Cardoso, Irene de Queiroz e Mello e Samuel 
No primeiro caso, diferentes acontecimentos favoreceram a elaboração de uma narrativa que sustentou as ações de realocação, como as chamadas "chuvas de abril" de 2010, a partir das quais foi possível acionar o argumento do "risco"3, bem como a realização da Copa do Mundo de 2014 e dos Jogos Olímpicos de 2016, cujo universo de sentido erigiu a expressão "legado” (Magalhães 2013). Tanto para evitar a proliferação das chamadas "áreas de risco", como para garantir um "legado" deixado pelos referidos megaeventos esportivos, as remoções passaram à ordem do dia como um dos modos possíveis de intervenção estatal sobre as favelas nesse período. No segundo, articulado a essa dimensão, o programa Minha Casa, Minha Vida criou as condições materiais necessárias para a efetivação da política de remoções, sem o qual esta talvez não tivesse alcançado a extensão observada. Não à toa, os números mais recentes (ainda que de difícil acesso), de acordo com a administração pública, informam que mais de 20 mil famílias foram retiradas de seus locais originais de moradia ${ }^{4}$.

Pude acompanhar in loco parte desse processo ${ }^{5}$, o que me permitiu verificar, desde dimensões infinitesimais, como ele se efetivou ao longo desse período. Um dos aspectos trabalhado neste artigo se constitui justamente na injunção entre a elaboração e a efetivação desse processo: a atuação estatal observada desde baixo, no contato cotidiano e ordinário entre agentes estatais, moradores de favelas e outros

Thomas Jaenisch (2015), do Observatório das Metrópoles, a gerente de trabalho social do referido programa na Secretaria Municipal de Habitação (SMH) afirmou que entre 2009 e 2012 foram inaugurados 49 conjuntos habitacionais, sendo 36 deles utilizados para reassentamentos. Corrobora a definição dos autores: "esses dados indicam que a Prefeitura do Rio de Janeiro tem usado massivamente o PMCMV para o deslocamento de famílias removidas de forma involuntária de seus locais originais de moradia”.

3. Sobre a construção e as consequências da justificativa do "risco", ver Magalhães (2016), Gonçalves (2015) e Mendes (2015)

4. Segundo a própria prefeitura, entre 2009 e o inicio de 2014, 20,3 mil famílias foram removidas. Dessas, 9,3 mil estão em imóveis do Minha Casa, Minha Vida, 5 mil recebem aluguel social e 6 mil foram indenizadas. Ver "Mais de 20 mil famílias foram removidas nos últimos quatro anos no Rio", Agência Brasil, 16 maio 2014.

5. Este artigo é baseado em minha tese de doutorado e em pesquisas posteriormente realizadas, momentos nos quais analisei os processos de remoção de favelas ocorridos nos últimos anos na cidade do Rio de Janeiro. Estive em aproximadamente 30 localidades entre 2009 e 2016, em diferentes regiões da cidade e fases do processo de remoção. Acompanhei mais detidamente algumas dessas experiências, das quais destaco as das favelas Metrô-Mangueira, Vila das Torres, Campinho, Parque Colúmbia (todas na Zona Norte), Estradinha-Tabajaras (Zona Sul), Vila Recreio II, Vila Harmonia e Vila Autódromo (todas na Zona Oeste). Como será possível observar, busquei acompanhar ocasiões de realocação em diversas áreas da cidade, o que me permitiu confirmar o aumento de escopo na atuação da administração pública em relação a esse tipo de intervenção sobre esses territórios. O tratamento das informações apresentadas se constituiu com base no acompanhamento in locu dessas dinâmicas, da consideração da miríade de documentos estatais e não-estatais produzidos pelos atores coletivos envolvidos e da produção midiática acerca do assunto. Esses materiais e as trajetórias dos indivíduos com os quais estabeleci interlocução no período considerado me permitiram perfazer os caminhos e meandros que produziram a configuração política na qual a retomada da remoção de favelas foi possível. 
atores que conformavam tais situações, que se reproduziram no tempo e no espaço, moldando uma determinada relação entre o Estado (em suas diferentes aparições e agenciamentos concretos) e os moradores dessas localidades.

Esse processo ocorreu através da mobilização de diferentes agências estatais, que conduziram distintos mecanismos que permitiram sua efetivação ${ }^{6}$. Tais práticas remocionistas constituíram um campo de forças no interior do qual se verificava a conformação empiricamente observável de formas de gestão estatal dessas populações.

Através desses mecanismos, operados nos interstícios do legal e ilegal, do formal e informal ${ }^{7}$, é possível perceber (e descrever) a maneira por meio da qual a trama urbana no Rio de Janeiro se constitui atualmente e como sua articulação produziu determinados efeitos sobre os moradores dessas favelas e também sobre o conjunto do tecido urbano.

Neste artigo busco apresentar, tomando por base a descrição etnográfica, duas dimensões interconectadas que estruturam esse processo: a da "lógica da intervenção" (Gros, 2009) e a questão da circulação. Isto é, as ações levadas a cabo pelos aparatos estatais nessas ocasiões de remoção se organizam pelo duplo aspecto de atuar sobre uma população em um meio físico específico e também sobre a circulação por entre diferentes escalas espaciais, organizando os fluxos (humanos, mas também de coisas) de acordo com certos efeitos esperados. Tal empreendimento analítico se apoiará na experiência dos moradores de uma favela da Zona Oeste da cidade do Rio de Janeiro (a Vila Recreio II) removida entre os anos de 2010 e 2011 em função da construção de uma via segregada para ônibus (o Bus Rapid Transport, BRT), obra esta incluída no rol daquelas que preparariam a cidade para os Jogos Olímpicos de 2016. O artigo apresenta, além desta introdução e das considerações finais, três seções: na segunda, busco mapear rapidamente a emergência da justificativa do legado como campo discursivo legitimador de intervenções como as remoções; na terceira, trato diretamente da configuração material (seus efeitos e consequências) da intervenção na favela mencionada e na vida de seus moradores; por fim, na quarta seção, apresento

6. Entendo por Estado a malha multiforme de relações e práticas perceptível do ponto de vista externo das técnicas e estratégias que utiliza e de seus efeitos concretos. Nesse sentido, cabe pensar o Estado não com base na busca de um fundamento último do poder, de um ser profundo do poder que pode ser alcançado, mas somente valendo-se de sua topografia, de ações e práticas que vão construindo uma verdadeira cartografia em que se visualizam os jogos de força que o traçam e constituem. Nessa angulação, um recurso heurístico interessante para pensar as situações de remoção é a noção de governamentalidade. Foucault a define como sendo o conjunto composto por análises, cálculos, táticas, instituições e procedimentos que permitem que seja exercida essa maneira específica de poder cujo objetivo principal é a gestão de uma população. Nesse sentido, interessariam as variadas técnicas de governo, entendidas como aquelas que permitirão conduzir as condutas e os movimentos de determinados indivíduos em um dado contexto e através de instrumentos estatais específicos.

7. Tomo por referência aqui as reflexões realizadas por Telles (2010). 
como se articulam essas duas formas de governar, a "intervenção" e o "fazer circular", e seus efeitos biopolíticos na constituição da cidade.

\section{A justificativa do "legado" dos Jogos Olímpicos de 2016}

As intervenções urbanísticas que prepararam a cidade para os megaeventos esportivos, notadamente a Copa do Mundo de 2014 e os Jogos Olímpicos de 2016, implicaram alterações significativas nos fluxos e usos do espaço da cidade, provocando, inclusive, o deslocamento de moradores de algumas favelas.

Os Jogos Olímpicos se configurariam, nessa conjuntura, como uma espécie de ancoragem moral que permitiu a dimensão assumida pelo reordenamento do espaço urbano no Rio de Janeiro, atualmente em curso, cuja justificativa fundamental é a do “legado”. Isto é, tais intervenções levadas a cabo pela administração pública ocorreriam em função do "legado" que os Jogos Olímpicos deixariam para a cidade. Nesse "pacote olímpico" foram incluídas, também, as ações estatais nas favelas, criando as condições para que as intervenções do tipo erradicação pudessem ganhar corpo e alcançar a dimensão que efetivamente atingiram. A elaboração narrativa que mobilizou a justificativa do legado se organizou de tal forma que buscou se sobrepujar a qualquer crítica. Nessa construção normativa, não se poderia ser contra algo que tão somente procuraria melhorar as condições de vida das pessoas, especialmente as mais pobres, e modernizar a cidade, cuja concretização se devia à realização dos Jogos.

A realização dos Jogos Olímpicos se apresenta, portanto, como uma "oportunidade" ${ }^{8}$ que não poderia ser desperdiçada, segundo afirmou o então prefeito Eduardo Paes em diferentes ocasiões em que justificava publicamente as intervenções urbanas em curso. A "oportunidade" aqui diz respeito ao fato de que essa seria a melhor ocasião para superar a lógica que teria feito com que a cidade fosse lançada na espiral de abandono e desordem que a caracterizaria atualmente.

Nesse enquadramento, produzido especialmente por autoridades públicas municipais, mas também por setores da imprensa, todo investimento público foi incluído e explicado como uma consequência da "conquista" das Olimpíadas. Foi justamente essa "oportunidade" que permitiu a emergência dos "legados" observáveis no espaço da cidade, como a "revitalização" de áreas anteriormente consideradas degradadas (como a que se realizou na zona portuária, através do projeto Porto Maravilha); através das obras viárias cujo resultado seria ligar e alterar usos de certas regiões (com

8. Um dos momentos em que essa enunciação apareceu de maneira mais elaborada foi durante a entrevista que o então prefeito Eduardo Paes deu ao programa Roda Viva, da Rede Brasil de Televisão, em março de 2011. Também nesse programa apareceu de forma detalhada a distinção e complementação entre o "legado físico" e o "legado da autoestima" que os Jogos Olímpicos deixariam para a cidade. 
os Bus Rapid Trans - BRTs); a construção de equipamentos culturais como o Museu do Amanhã; e, até certo ponto, a edificação de inúmeros conjuntos habitacionais que redefiniram a paisagem das periferias cariocas.

\section{Consequências das remoções: o caso da Vila Recreio ॥}

Nesta seção, apresentarei e analisarei algumas consequências do processo de remoção vivenciado pelos moradores da Vila Recreio II, favela removida entre 2010 e 2011, cuja justificativa oficial à época foi a construção da via Transoeste ${ }^{9}$, uma das obras tratadas como um dos "legados" dos Jogos Olímpicos de 2016. Demonstrarei como diferentes estratégias e mecanismos de gestão são operados concretamente pelos aparatos estatais para efetivar tal processo. O objetivo aqui é compreender como essas circunstâncias se organizam em diferentes planos que se superpõem, tramando uma determinada maneira de constituição (e de governo) do espaço urbano na atual conjuntura da cidade do Rio de Janeiro.

FIGURA 1

Localização da Vila Recreio II antes da remoção

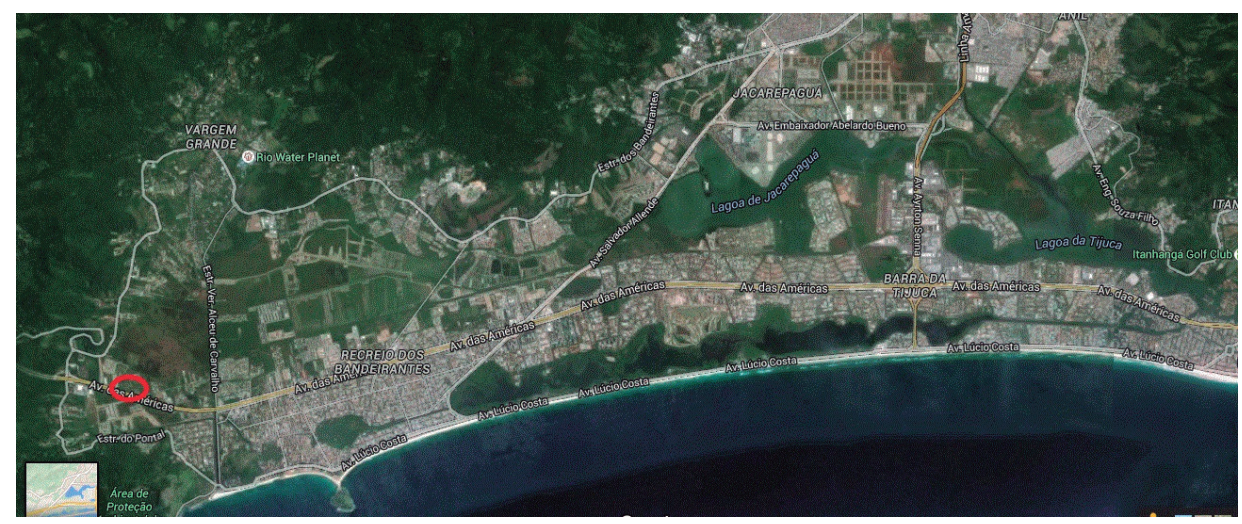

A marcação em vermelho indica a região onde estava localizada a Vila Recreio II, no bairro do Recreio dos Bandeirantes, Zona Oeste da cidade.

Quando do lançamento da obra, em 2010, o prefeito Eduardo Paes, diante de um selecionado público formado por algumas autoridades públicas e moradores dos condomínios de classe média alta da região, fez um discurso no qual abordava a importância da construção da referida via para a cidade, sem mencionar o que ocor-

9. Essa via faz a ligação entre os bairros da Barra da Tijuca e o de Santa Cruz, ambos na Zona Oeste da cidade. 
reria com as favelas que seriam afetadas por estarem no traçado original do projeto apresentado durante a sua exposição.

$\mathrm{Na}$ sequência, ressaltou que a situação dessas localidades “já estava resolvida”, sem detalhar o que isso significava. Após esse breve comentário acerca das favelas, e para evitar qualquer questionamento, ele saiu pela lateral do palco instalado no local. Alguns moradores da Vila Recreio II que estavam presentes foram atrás dele para saber mais informações sobre sua situação. Em uma rápida conversa, o prefeito disse a eles que ficassem tranquilos, pois "ninguém perderia nada”, e que "tudo seria organizado", confirmando a intenção da administração pública de retirá-los de suas casas.

Os moradores afirmaram que esse comentário foi feito em tom de voz baixo para, na avaliação deles, evitar que ocorresse algum tipo de reação que pudesse ser considerada intempestiva, uma vez que isso poderia fazer com que a situação saísse do controle do prefeito, desconstruindo todo aquele cenário montado para legitimar a intervenção estatal naquela região. Contudo, tudo o que ocorreu depois foi completamente diferente do que ele afirmara naquele dia.

Após algumas semanas, a remoção teria início. Somente após esse processo ter avançado bastante e muitos moradores terem sido removidos, a Secretaria Municipal de Habitação (SMH) realizou reuniões com os habitantes locais. Nesses encontros, os moradores, que contavam com a presença de defensores públicos do Núcleo de Terras e Habitação da Defensoria Pública (NUTH), exigiam, além da permanência, melhores condições de indenização e mesmo pedidos para respeitar prazos de desocupação (para aqueles que foram convencidos a sair), algo que não estava ocorrendo $^{10}$. Em uma dessas ocasiões, em dezembro de 2010, próximo à época de Natal, eles solicitaram que o processo de remoção fosse interrompido, ao menos temporariamente, o que seria aceito inicialmente pelo secretário. Entretanto, no dia 23 de dezembro, eles foram surpreendidos com a chegada de diversas equipes de demolição e da Guarda Municipal. Naquele dia, diferentes casas vieram abaixo, evidenciando o descumprimento da promessa feita anteriormente pelo secretário de habitação aos moradores.

10. Embora não tenha sido o foco deste texto, os moradores de favelas e um conjunto de coletivos lograram constituir o que chamei em outro lugar de uma "trama movimentalista" (Magalhães, 2017), na qual se produziram circuitos e percursos pelo qual circulavam críticas e denúncias aos processos de remoção então em curso naquele momento. Considero que se efetivou uma articulação circunstancial entre diferentes atores, individuais e coletivos, que era formada basicamente pelos moradores de favelas - e suas comissões -, o NUTH e a Pastoral de Favelas, articulação em torno da qual orbitava uma miríade de outros grupos que intentavam constituir formas as mais variadas de resistência àquele processo. 
Tal circunstância evidencia uma das maneiras pelas quais se efetivam esses processos e torna possível apreender a operação de um mecanismo de gestão dessas situações: certo jogo de expectativas operado por agentes públicos num universo relacional atravessado por relações desiguais de poder. Isto é, ao passo que responde a uma demanda daqueles moradores, a administração pública, investida de todo um aparato de força, impede que aquela demanda seja processada no tempo das expectativas dos moradores, visto que ocorre em outra temporalidade, marcada aqui pela lógica da "necessidade" de realização da obra.

Com as remoções ocorrendo a pleno vapor, os moradores que ainda resistiam, através de uma Ação Civil Pública impetrada pelo NUTH, recorreram à justiça em fevereiro de 2011. Algum tempo depois, eles obtiveram uma decisão judicial que suspendeu as demolições e determinava uma nova avaliação das casas, designando para isso um perito responsável, já que a primeira estimativa havia sido feita apenas com base em uma análise exterior das habitações.

Logo depois, o perito designado foi à Vila Recreio II fazer a medição das construções que ainda restavam. Entretanto, o resultado dessa nova avaliação determinou um valor de indenização pouco acima daquele ofertado pela administração pública inicialmente a algumas famílias. O perito teria comunicado aos moradores que não poderia colocar o "preço real" porque as habitações da favela em que moravam eram de "posse". Contudo, moradores afirmaram que eles tinham o registro formal dessa posse e que faziam questão de exigir algo melhor, caso tivessem que sair de suas residências.

Essa situação apresenta um dos mecanismos agenciados nessas ocasiões de remoção. Ele diz respeito à natureza jurídica da existência das favelas. Neste caso muito específico, mas também em outros, uma das formas para efetivar a realocação era a utilização do argumento de que a área não pertencia aos moradores e, portanto, estaria passível de ser retirada em função do “interesse público”. Mais do que isso, as ações da administração pública se organizavam nas fronteiras muitas vezes borradas entre o legal e o ilegal, tal como se pode observar nessa questão da "posse”.

Há duas ordens de consideração aqui. Primeiro, o ordenamento jurídico brasileiro atual admite a posse como uma das maneiras de reconhecer a ocupação de determinadas áreas por parte de certos grupos de pessoas ${ }^{11}$. Contudo, no interior mesmo do sistema de justiça, esse reconhecimento pode ser questionado por ou-

11. Na legislação brasileira há diferentes maneiras de reconhecer a posse de uma dada área: o usucapião, forma aplicada quando a área for privada; Concessão Especial de Uso para Fins de Moradia (CUEM), voltado para áreas públicas ocupadas; Concessão de Direito Real de Uso, quando a administração pública transfere para o particular um terreno público para utilização em fins específicos e sob certas condições; por fim, há o dispositivo da Regularização Fundiária de Interesse Social. 
tros instrumentos jurídicos, como, por exemplo, o direito de propriedade e mesmo valendo-se do chamado "interesse público"12 atrelado a alguma intervenção urbana que, a principio, visaria melhorar as condições de vida da população.

Em segundo lugar, a própria existência histórica das favelas as situa num limiar muito tênue entre o reconhecimento legal e a ilegalidade ${ }^{13}$. No caso do Rio de Janeiro, embora muitas dessas áreas estejam consolidadas há muitas décadas, poucas tiveram reconhecimento legal com base nos instrumentos existentes para tal. É nesse terreno nebuloso da existência legal das favelas que a administração pública atuará de maneira decisiva. Como a "posse" é algo instável, permite-se que um perito afirme que um "valor maior" de indenização não seja possível, ao passo que o processo de remoção tenha continuidade aparentemente sem grandes questionamentos.

\section{A vida entre os escombros: descaracterização e destruição}

Após o período em que ocorreu boa parte das remoções e mesmo depois da ordem judicial, as ações da administração pública continuaram. Na medida em que os moradores iam sendo retirados, o aparato municipal destruía as casas esvaziadas. A Vila Recreio II se transformou num local inabitável pela própria ação da prefeitura. Escombros por toda a parte, ferros retorcidos expostos, água acumulada das chuvas provocavam diferentes transtornos a quem ainda permanecia. A companhia de energia elétrica, ainda durante a vigência da liminar que garantia a permanência de alguns moradores, cortou o fornecimento do serviço sem maiores explicações em diversas ocasiões.

Isso nos remete às reflexões de Mendiola (2017), quando o autor afirma que essas táticas e estratégias dizem respeito ao modo através do qual o sujeito, nessas situações, é decomposto, justamente por ser levado a uma geografia que se constitui para necessariamente causar dano, num processo contínuo de desfazimento da vida (Das, 2007). Como afirma Mendiola (2017), trata-se de ocasiões em que se passa a habitar aquilo em que dificilmente há algo reconhecível, onde se vivencia um espaço

12. A prefeitura realiza as ações de desapropriação através do Decreto-Lei 3.365/41, válido para todo o país. O seu artigo $2^{\circ}$ apresenta a seguinte definição: "mediante declaração de utilidade pública, todos os bens poderão ser desapropriados pela União, pelos Estados, Municípios, Distrito Federal e Territórios”. Esse ato de declarar como de utilidade pública determinadas áreas da cidade é um ato discricionário do Poder Executivo. Este, por meio de um decreto municipal, apresenta quais imóveis serão desapropriados a favor da chamada "utilidade pública". O papel representado pela discricionariedade aqui é importante para compreender como o "interesse público" articula jogos de poder específico. Como afirma Costa (2014): “a própria legislação empresta um alto grau de discricionariedade ao poder público, garantindo total liberdade ao Poder Executivo para decidir o que é de 'interesse público 'ou não”.

13. Sobre a variação histórica entre o reconhecimento legal e a ilegalidade das favelas, ver Gonçalves (2013). 
que foi imerso em um processo que o torna radicalmente estranho, um espaço que parece esgotar a possibilidade de poder ser habitado, que o autor define como sendo o inabitável.

A primeira ação da administração pública após a efetivação do pagamento das indenizações ou mesmo após a aceitação de uma nova unidade habitacional seria aquilo que os agentes públicos chamam de "descaracterização", isto é, a construção não seria demolida imediatamente, mas apenas algumas de suas partes, sendo abertos buracos na laje e nas paredes. Em alguns casos, isso acaba provocando danos, que podem ser irreversíveis, na casa ao lado. Em muitas localidades em que estive pude perceber como casas foram danificadas por esse procedimento.

Moradores que tiveram suas moradias prejudicadas pela descaracterização de outra ficaram preocupados e decidiram aceitar a proposta feita pelos agentes públicos. Autoridades públicas, quando questionadas sobre a imediata demolição das casas, justificavam-se afirmando que este procedimento seria necessário para que a localidade não fosse reocupada.

A demolição das casas realizada pelo maquinário mobilizado pelo aparato estatal produzia um cenário no qual os moradores eram instados a conviver com um conjunto de obstáculos que eram, ao mesmo tempo, físicos e simbólicos. Isto é, os restos das demolições, as casas semidestruídas, paredes prestes a cair a qualquer momento, vergalhões à mostra, canos estourados, redes elétricas danificadas e espalhadas pelo terreno, significavam a dupla natureza da destruição à qual estavam sendo submetidos: tanto a que impactava suas moradias e a geografia local, quanto aquela que atingia suas redes de relações e as referências anteriormente projetadas na forma assumida pela localidade ao longo dos anos.

\section{A ação estatal entre o legal e o extralegal}

Tais práticas permitem localizar a ação da administração pública como se constituindo nas fronteiras entre o legal e o ilegal, como já afirmado. Isso se visualiza, uma vez mais, quando consideramos o encadeamento de sequências de situações descritas a seguir. Em meados de abril de 2011 (e ainda na vigência da liminar mencionada anteriormente), operários da empreiteira responsável pela obra e representantes da subprefeitura, apoiados pela Guarda Municipal, derrubaram a casa de uma moradora com todos os seus pertences no interior. Desesperada, ela ainda pediu para retirar seus móveis, mas os agentes públicos não permitiram e, logo em seguida, deram inicio a destruição, que incluiu seu material de trabalho como ambulante. Essa moradora ainda conseguiu salvar algumas poucas coisas, mas nunca foi ressarcida pelos objetos destruídos pelos agentes públicos. 
Na mesma ocasião, outra moradora daquela localidade estava passando de ônibus no momento e, ao observar aquela ação da prefeitura, desceu do transporte e resolveu intervir. Ela apontou que os representantes da subprefeitura presentes apresentaram documentos falsos, que diziam que a liminar que impedia as demolições havia sido cassada. Segundo afirmou, como se não bastasse apresentar um documento irregular para justificar a investida, um deles ainda tentou legitimá-la ao acionar uma suposta inscrição institucional como delegado de polícia, numa tentativa de intimidar os moradores e dar curso às atividades de destruição dos imóveis.

Não satisfeita com o desenrolar dos acontecimentos, a moradora citada acima exigiu o documento que dizia que a liminar havia sido revogada, mas os funcionários da subprefeitura não quiseram lhe mostrar. Ela insistiu e, após alguns instantes, eles cederam. Quando ela percebeu que o documento não tinha validade para a ação que estava sendo empreendida, imediatamente chamou os guardas municipais presentes, os funcionários da empreiteira, o pessoal da mudança e, numa evidente tentativa de angariar apoio naquela circunstância crítica com base nos instrumentos que tinha disponível, apontou para eles que a Constituição Federal e as legislações estaduais e municipais afirmam que "uma ordem absurda não se cumpre".

A situação ainda apresentaria novos desdobramentos. Ela disse que aquilo que faziam era um crime e, quando os agentes públicos já estavam no portão de sua casa, abriu-o e disse a eles que poderiam entrar, mas sabendo que estavam cometendo uma grave violação das leis vigentes. Um impasse se formou. Parecia que a interpelação da moradora produzira algum efeito. Os funcionários e operários ficaram confusos sobre o que estava acontecendo e não entraram. Os próprios guardas municipais que acompanhavam toda a situação concordaram com o que ela estava falando.

A cena final dessa curta, porém intensa, situação de tensão se deu quando os moradores contataram a Defensoria Pública. Uma defensora pública conseguiu acionar o juiz responsável pela liminar que impedia as demolições e este, por sua vez, entrou em contato com os funcionários da subprefeitura presentes naquela situação, dizendo-lhes para interromper as ações e informando-lhes que, caso continuassem, poderia lhes dar ordem de prisão.

\section{Na trama dos documentos}

De acordo com diferentes moradores, nenhum daqueles que aceitaram a oferta da prefeitura havia recebido integralmente os valores das indenizações que lhes estavam destinadas, mesmo sendo muito baixas. Isso ocorreu mesmo com aqueles que saíram no inicio do processo de remoção. Havia uma diferença considerável entre o valor 
que havia sido oferecido e o que efetivamente fora dado às pessoas, e em alguns casos a defasagem chamava a atenção: variava entre 50 e 700 reais.

Diante dessa situação, alguns moradores foram à SMH questionar e afirmar que não assinariam nenhum documento, confirmando o recebimento da indenização, enquanto essa questão da defasagem dos valores não tivesse sido resolvida. Entretanto, na secretaria lhes fora dito, segundo afirmaram, em tom ameaçador, que se o morador se recusasse a aceitar aquele valor naquele momento, por conta desse questionamento, quando fosse receber posteriormente, o valor sofreria mais um desconto.

Além disso, no ato de recebimento dos valores impostos pela administração pública, todos foram obrigados a assinar outro documento no qual se informava a transferência da terra em que moravam para a prefeitura, mas sem uma explicação aos moradores sobre as possíveis consequências futuras dessa assinatura. Apesar de terem assinado tal documento, foi-lhes impedido o acesso a uma cópia do mesmo, também não havendo explicações para isso.

Em relação a esse tipo de prática, isto é, documentos que são assinados sem se saber o seu teor ou sequer se ter acesso a uma cópia, é possível destacar outra situação que configura uma ocasião em que há certo embotamento entre o legal e o ilegal, em cujas dobras se organizam diferentes práticas caracterizadas pelos próprios moradores como pressão e coação.

Uma moradora da localidade em questão possuía uma padaria na mesma construção em que morava. Em relação à casa, ela recebeu um determinado valor de indenização, assinando um documento em que essas informações eram discriminadas. De forma completamente duvidosa, logo após, funcionários da prefeitura lhe deram outro documento, só com o nome dela, CPF e completamente em branco. Preocupada e confusa diante da pressão para que ela assinasse rapidamente, ela assim o fez. A senhora ainda questionou o fato daquela folha estar em branco, mas os agentes públicos que foram até a sua casa disseram que era assim mesmo. Logo após a assinatura, sua casa foi derrubada. Não se sabe o que fizeram com aquela folha em branco assinada.

Diferentes documentos circulam nessas situações de remoção e eles inscrevem e circunscrevem pessoas, coisas e seus destinos. As pessoas envolvidas com/por esses documentos, especialmente os moradores, no ato em que os assinam, acabam por se comprometer com uma ordem de definições e ações que foram previamente estabelecidos pelas agências estatais.

Como foi possível observar, as ações estatais parecem produzir uma confusão sistemática, provocando dúvidas nos moradores quanto a que tipo de documento já se assinou e qual o grau de comprometimento a partir desse ato. Esse conjunto de documentos, apresentados a esses moradores, produzem medo e receio, na medida em que, ao inscrevê-los num dado processo, em relação ao qual se sabe muito pouco, 
gera-se um tipo de constatação de que, a qualquer momento, qualquer coisa pode-lhes acontecer.

Tal situação de incerteza acaba por se tornar uma fonte de instabilidade considerável, alterando-lhes a autopercepção quanto à continuidade das rotinas de vida. Além disso, é importante mencionar que tal configuração expressa as maneiras através das quais se constitui a possibilidade de gerir essa população, conformando uma dinâmica de coprodução contínua do Estado e suas margens.

É importante notar, tal como ressaltam Das e Poole (2004), que as práticas de levantamento documental do Estado se organizam de acordo com a possibilidade de consolidar o controle estatal sobre os sujeitos, as populações, os territórios e as vidas. O que a descrição dessas cenas envolvendo o agenciamento de certos documentos revela é que há, como ainda afirmam as autoras, diferentes espaços, formas e práticas através das quais o Estado está constantemente sendo experimentado e desconstruído mediante a ilegibilidade de suas próprias práticas, documentos e palavras.

O que emerge dessas práticas não seria tanto como os diferentes aparatos estatais tornam certa população legível para si, mas, fundamentalmente, como esses documentos se encarnam em formas de vida através das quais certas ideias de sujeitos e cidadãos começam a circular entre aqueles que utilizam esses documentos (Das e Poole, 2004).

\section{0 controle das condutas através do mecanismo do endividamento}

Outra consequência observada durante esses processos de remoção diz respeito ao endividamento. Ou seja, durante e após a remoção, diferentemente do que afirmava o discurso oficial, diversos moradores foram obrigados a tomar empréstimos, formal ou informalmente, para poder cobrir custos e gastos que a ação da administração pública ocasionou com o processo de remoção. Isso ocorreu especialmente no caso daqueles que possuíam alguma atividade econômica na qual empregavam certa quantidade de pessoas e, para regularizar as demissões, tiveram que contrair empréstimos em uma situação de queda nos rendimentos, já que o cenário de destruição afastava potenciais clientes dos serviços. Essa situação também pode ser visualizada no pós-remoção, especialmente quando se considera aquelas pessoas que tiveram que sair de suas casas antes que a indenização fosse efetivamente paga ou mesmo quando esse valor era muito baixo, o que dificultava, por exemplo, a compra ou o aluguel de outro imóvel.

Em um desses casos, uma ex-moradora da Vila Recreio II conseguiu alugar um novo imóvel, mas com muita dificuldade, já que não havia recebido a indenização antes de sair da localidade. Naquela ocasião, ela pagava $\mathrm{R} \$ 540$ de aluguel numa casa em uma favela próxima. Ela apontou que teve que conseguir emprestado $\mathrm{R} \$ 1620$, 
pois a locatária exigiu um valor de depósito na forma de adiantamento. E seus custos só aumentavam. Por exemplo, durante o período em que alugou o referido imóvel, ela teve que pagar aproximadamente $\mathrm{R} \$ 100$ por mês de energia elétrica, custo que não possuía antes na localidade em que morava. Além disso, passou a enfrentar diferentes dificuldades em seu cotidiano, como não conseguir comprar todos os itens para sua casa, inclusive alimentação, afirmando que fora obrigada a realizar uma escolha: "se compro um item, não dá para comprar outro". Ela avalia toda essa situação como negativa, uma vez que isso nunca havia acontecido em sua vida, nem mesmo quando estava sozinha, com seus filhos e sem apoio.

Outro morador apontou que teve que pedir ajuda aos filhos. Explicou que enquanto eram crianças e adolescentes nunca exigiu que trabalhassem, mas que apenas estudassem. Afirmou também que, em todo o período em que morava na localidade, nunca pagou aluguel. Entretanto, diante da situação de vulnerabilidade em que se encontrava no pós-remoção, teve que recorrer aos filhos, mesmo estes tendo salários muito baixos. Afirmou que, por conta das dificuldades, acabou com as poucas reservas que sua filha conseguiu reunir em todo o tempo em que estava trabalhando. Apontou também que o último aluguel da casa em que moravam temporariamente em outra favela fora pago por ela, além da conta de luz e telefone. Ressaltou que sua família não tem mais nada e suas rendas ficaram comprometidas com dívidas, que antes não possuíam. Afirmou que se tentasse quitar a dívida que adquiriu com os próprios filhos, a indenização que a administração pública lhe ofereceu (em torno de R \$ 14 mil e que naquele momento ainda estava retida) não seria suficiente para pagá-los.

Essa questão do endividamento se torna mais complexa na medida em que diversos moradores perderam o emprego durante os processos de remoção. Isso ocorreu, fundamentalmente, em duas situações: primeiro, no início do processo, devido à intensa investida dos aparatos estatais. Isso se dava, pois havia a preocupação muito recorrente entre as pessoas de que a sua casa poderia ser derrubada a qualquer momento, já que não havia (assim como não há até hoje) nenhum critério ou planejamento quanto ao trabalho de demolição. Sendo assim, por medo, muitos moradores faltavam ao trabalho, no caso daqueles que possuíam atividade formal, ou simplesmente abandonavam a atividade da qual extraiam alguma renda, no caso daqueles trabalhadores informais. Outro motivo para a perda do emprego vinha das ameaças feitas pelos agentes públicos: a prefeitura marcava um determinava data para que o morador fosse até a SMH, por exemplo. Entretanto, em muitas ocasiões, desmarcava em cima da hora. Um dia de trabalho era perdido. Isso ocorreu dezenas de vezes. Funcionários da prefeitura, ao serem contatados pelos moradores, costumavam dizer o seguinte: "marcamos hoje, mas não vai dar tempo de atender. Volte outro dia". 
A lógica da intervenção e a questão da circulação: as remoções de favelas como forma de gerir o espaço urbano

Seguir a constituição das situações acima descritas permitiu reconstruir a maneira pela qual diferentes técnicas de controle e gestão são criadas, mobilizadas, conduzidas e reconduzidas em diversas ocasiões em que se concretizava um determinado processo de remoção. Todas essas técnicas buscaram, em um determinado campo de forças por elas instaurado, conduzir e controlar moradores de favelas, a partir de uma intervenção que implicava por em circulação um conjunto de pessoas pelo espaço urbano.

Quando Foucault aborda a questão dos dispositivos de segurança, ou da "sociedade da segurança", isto é, mecanismos com base nos quais se intervém não mais sobre um individuo ou um conjunto específico de indivíduos cerrados em um determinado espaço, mas sobre o conjunto da população, ele ressalta o fato de que, para a ação estatal, não se trata somente de definir fronteiras ou mesmo determinar certas localizações (como nos mecanismos disciplinares), mas, principalmente "possibilitar, garantir, assegurar circulações: circulação de pessoas, circulação de mercadorias, circulação do ar etc." (Foucault, 2008, p. 39).

Os processos de remoção já terminados ou ainda em curso na cidade do Rio de Janeiro, além de inúmeras outras intervenções urbanas levadas a cabo nos últimos anos, produziram uma reconfiguração significativa no espaço citadino. Particularmente no que se refere às favelas, foco principal deste trabalho, a ação estatal levou a uma redistribuição espacial considerável dessa camada da população, na medida em que implicou a retirada de moradores de diferentes favelas, de diversas regiões da cidade. Essa realocação foi feita de distintas maneiras, uma vez que, dependendo da opção dada às pessoas (indenização, compra assistida ou um novo imóvel num conjunto habitacional), diferiria a região para a qual ela seria direcionada.

No caso da indenização e da compra assistida, aumentava-se a possibilidade de permanecer tanto no mesmo local de moradia original (naqueles casos em que apenas parte da favela fora removida), embora a circulação da notícia de que a prefeitura havia definido essa opção fizesse com que os preços dos imóveis na região aumentassem consideravelmente. Entretanto, apesar dessa virtual possibilidade, muitas vezes não foi exatamente dessa forma que se passou. Em função dos baixos valores recebidos a título de indenização em alguns casos, ocorreu uma significativa pulverização de moradores por várias áreas da cidade, constituindo-se novos núcleos habitacionais formados pelos antigos residentes das favelas removidas.

Em um caso que pude acompanhar, em que a moradora recusou a alternativa de um imóvel em conjunto habitacional, a indenização foi insuficiente para a obtenção imediata de uma nova moradia. Nesse caso, a proprietária do imóvel demolido rece- 
FIGURA 2

Mapa de reassentamentos

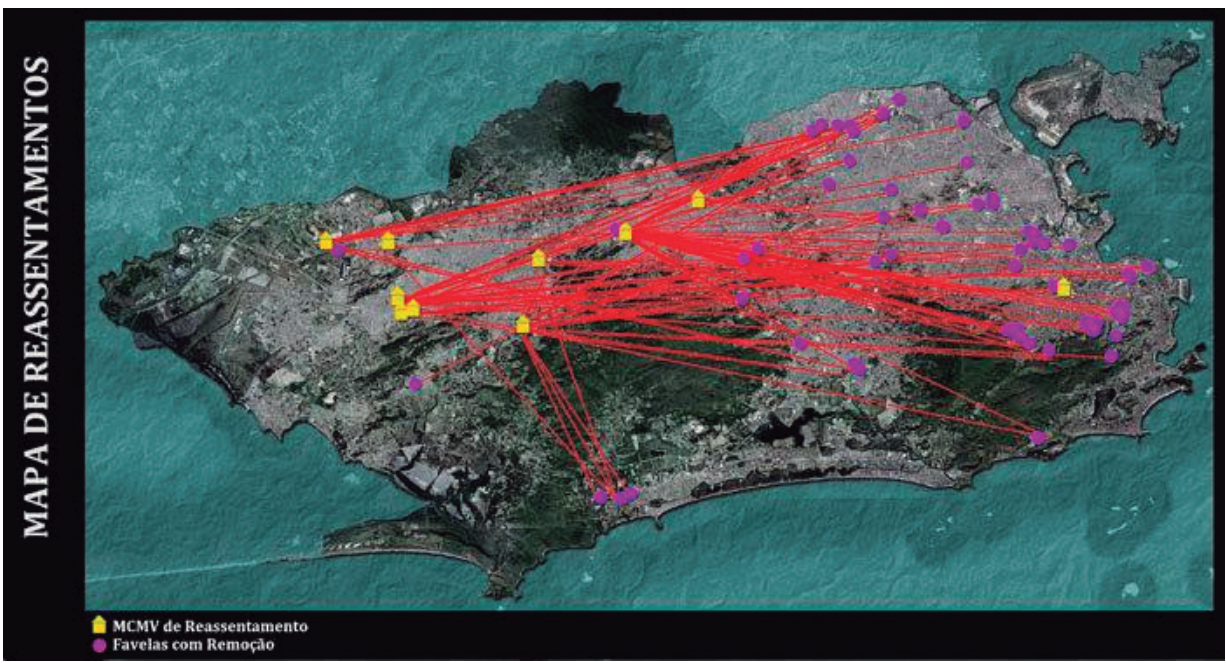

Fonte: Mapa produzido por Lucas Faulhaber (2013).

beu 13 mil reais de indenização. Ela também possuía uma construção que funcionava como um comércio, sua principal fonte de renda, que ficava logo embaixo de sua casa. Entretanto, naquele momento, a administração pública alegou que, em função da ilegalidade daquela atividade econômica, não poderia ressarci-la por isso. Findo o processo de remoção e demolidos seu comércio e sua casa, ela fez uma verdadeira peregrinação até conseguir se estabelecer no local em que se encontra atualmente. Sem emprego e endividada, especialmente em função dos prejuízos que aferiu com a destruição de seu comércio, ela inicialmente se deslocou para a casa de sua filha, que se localizava em outra favela da região. Isso ocorreu, pois, não lhe fora dado tempo viável para encontrar um novo imóvel antes que o antigo fosse derrubado. Durante algum tempo, teve que conciliar a busca por um novo emprego com a de uma nova casa. Em função do valor recebido, ela sequer cogitou procurar em uma área formal da cidade, concentrando suas buscas em outras favelas próximas daquela na qual morava. Amparada por sua filha, mas considerando-se um incômodo, intensificou as buscas e, quase um ano depois, encontrou uma casa inacabada, sem portas e janelas, em outra favela da região.

Em outro caso, após mobilização local que se constituiu contra o processo de remoção, mas que não logrou completo êxito, a administração pública ofereceu, além do imóvel e da indenização, a “compra assistida”. Essa possibilidade implica que a própria administração, até um determinado valor, normalmente pouco maior que o da indenização, responsabiliza-se por ajudar a comprar um novo imóvel para o morador, principalmente no mesmo local em que morava anteriormente (quando 
for o caso) ou na própria região onde se localizava a favela. O procedimento consistia no seguinte: o próprio morador em questão faria um levantamento de um novo imóvel, levando em consideração o valor, e o apresentaria à Secretária Municipal de Habitação, que avaliaria e liberaria o dinheiro para confirmar a compra. Entretanto, em muitos casos, não fora possível obter imediatamente um novo imóvel.

Um exemplo dessa situação ocorreu com a moradora de uma favela removida em função de uma obra viária na Zona Norte da cidade. Após ser contemplada com essa opção, ela também realizou um percurso parecido com o anterior, no que se refere à impossibilidade de, imediatamente, obter uma nova moradia. Como também não tivera um prazo estendido para conseguir outra casa, ela foi morar de favor, durante certo período, na casa de parentes, que, tal como no outro caso, também ficava localizada em outra favela, em outra região da cidade. Assim como no outro caso, ela ficara desempregada em função do processo de remoção, já que perdeu o emprego por ter acompanhado as inúmeras fases do processo de realocação. Mais uma vez, a busca era dupla: por emprego e moradia. Em relação a esta última, sua maior dificuldade fora encontrar um imóvel na mesma região em que morava anteriormente. Sua intenção, como ela me relatou em entrevista, era a de permanecer na área, pois fora ali que sua vida havia sido construída e onde sua filha constituíra inúmeros laços, especialmente os estabelecidos na escola, que ali ficava. Embora também tenha considerado a possibilidade de obter uma nova casa em outra favela, suas buscas acabariam se concentrando na parte formal do bairro.

Nesse sentido, conseguir o imóvel se tornou uma tarefa cansativa, embora persistente. Ela visitou inúmeras residências, mas, além daquelas de que não gostava ou que apresentavam problemas, a principal questão era o limite dado pela SMH em relação ao preço. Em função disso, sua busca demorou muitos meses, embora não tenha chegado a um ano como no outro caso. Novamente: não bastava apenas achar e gostar de um determinado imóvel. Ela teria de considerar, em primeiro lugar, seu valor e, em segundo, se a SMH aprovaria a compra. Após algum tempo, finalmente ela conseguiu confirmar a compra de um novo imóvel e, assim, poder sair da casa de seus parentes.

Situação diversa foi aquela vivenciada por aqueles que aceitaram um novo imóvel no conjunto habitacional construído pelo programa Minha Casa, Minha Vida. Seu deslocamento, não menos problemático que nos outros casos, foi feito diretamente para essas unidades, normalmente em regióes muito distantes daquelas que originalmente moravam, tal como destacado pelos fluxos presentes no mapa apresentado na Figura 2. O mapa mostra, basicamente, os deslocamentos feitos pelos moradores das favelas ou trechos de favelas removidas pela prefeitura do Rio de Janeiro entre 2009 e 2012. Como pode ser observado, as regiões de "saída" seriam as Zonas Sul, Zona Norte/subúrbio e Baixada de Jacarepaguá (Barra da Tijuca, Jacarepaguá e 
Recreio dos Bandeirantes). A região de "chegada" se concentrou basicamente na Zona Oeste, onde justamente foi construída a maioria dos conjuntos habitacionais no último período.

Nessa configuração é que se tornou compreensível a intervenção estatal no espaço urbano carioca e, mais precisamente, em suas favelas. Como aponta Hirata (2010), sustentando-se em Foucault, "se a população é o nível pertinente da análise, a circulação é a sua dinâmica”, isto é, controlar ou incitar a circulação populacional irá permitir que se separem as cadeias de efeitos que levam a uma circulação desejável (ou circulações desejáveis), tornando mínimos os considerados perigos inerentes e elevando ao máximo os seus efeitos positivos.

Ainda segundo o mesmo autor, o governo dos mecanismos de segurança organizaria suas formas de atuação através da condução das condutas, que seriam operacionalizadas mediante uma ação à distância, mas também valendo-se de uma intervenção no meio. De acordo com Foucault (2008), "meio" seria o suporte e o elemento que constitui a circulação de uma ação. Seria, sobretudo, aquilo onde se faria a circulação. De acordo com o autor,

[... ] o meio é um conjunto de dados naturais, nos pântanos, morros, é um conjunto de dados artificiais, aglomeração de indivíduos, aglomeração de casas, etc. O meio é certo número de efeitos, que são efeitos de massa que agem sobre todos os que aí residem. É um elemento dentro do qual se faz um encadeamento circular dos efeitos e das causas, já que o que é efeito, de um lado, vai se tornar causa, do outro (2008, p. 28).

Segundo afirma Barbosa, apoiando-se em Gómez, a "sociedade da segurança" produziria “espaços de segurança”, que se comporiam "em um meio ambiente artificial, através de intervenções urbanísticas, arquitetônicas e sanitárias sobre o espaço, buscando favorecer e regular certo tipo de mobilidade e de conduta" (2013, p. 162). Nesse sentindo, portanto, não se trata, tal como na disciplina, de uma intervenção sobre o corpo, e sim sobre o meio, "normalizando as condutas e afetando as condições de vida da população".

Como ressalta Foucault, o meio surge, portanto, como um "campo de intervenção". Isso aponta para o fato de que, por um lado, ao contrário de agir sobre indivíduos enquanto um conjunto de sujeitos de direito que seriam capazes de realizar ações voluntárias e, por outro, atingi-los como uma multiplicidade de organismos, "de corpos capazes de desempenhos, e de desempenhos requeridos como na disciplina", procurar-se-ia alcançar uma população, ou seja, "uma multiplicidade de indivíduos que são e que só existem profunda, essencial, biologicamente ligados à materialidade dentro da qual existem" (2008, p. 28). 
Essas referências se tornam importantes principalmente pelo fato de que, como já mencionado no início, atualmente operaria o que Telles (2010), citando Frederic Gros, chama de "lógica da intervenção". Marcando uma passagem decisiva entre o "tempo da política" e o da "administração das urgências", essa lógica aponta para o fato de que, inversamente ao que ocorreria na política (considerando seus protocolos de deliberação e negociação), a intervenção seria conduzida por critérios chamados técnicos de competência daqueles considerados como especialistas e "é acionada para restaurar uma ordem ameaçada, restabelecer harmonias rompidas, reparar disfunções, encontrar soluções” (p. 157). A intervenção visa à gestão dos riscos, constituindo-se de maneira pontual, em uma dada territorialidade, mas sempre de forma deslocante, na medida em que os alvos e os problemas podem ser redefinidos. Como ressalta a autora: "modos de gestão das populações, de seus fluxos e movimentos" (p. 157).

\section{Considerações finais}

Por em circulação, mover, retirar, deslocar, movimentar, produzir fluxos, reorientá-los, direcioná-los: esses termos podem ser aqui entendidos como a cifra a partir da qual é possível situar as práticas remocionistas ora em análise, tomando como sustentação analítica as experiências que ocorreram recentemente na cidade do Rio de Janeiro. Nessa configuração, as situações de remoções experimentadas pelos moradores de favelas e levadas a cabo pela administração pública municipal podem ser compreendidas indexando-as, para usar a terminologia etnometodológica, a um quadro em que os grandes projetos políticos - especialmente aqueles cuja base era a possibilidade da integração social - são deslocados em favor da lógica da intervenção e da administração, notadamente a administração das urgências.

No contexto da cidade do Rio de Janeiro dos Jogos Olímpicos, é possível perceber, tal como aponta Gros (2009), que ações de intervenção como essas que configuram as práticas remocionistas estão a serviço de uma determinada concepção de ordem e, para que essa se efetive, é necessário neutralizar - não necessariamente eliminar aqueles que podem se apresentar como seus possíveis perturbadores. O objetivo da intervenção, em última instância, não é acabar com determinados problemas, mas restabelecer fluxos interrompidos ou mesmo modificar aqueles já existentes, reconfigurando suas direções.

É nesse sentido que diferentes estratégias e mecanismos de controle foram experimentados e efetivados para fazer remover os moradores de favelas tanto no caso aqui analisado quanto em outros tantos que pontuaram a cena política urbana recente no Rio de Janeiro. Tais experimentações biopoliticas produziram uma situação de extrema indeterminação, na qual a própria vida passou a girar momentaneamente 
num vazio de sentido. Destaquei, entre outros mecanismos de controle, a ilegibilidade das práticas e documentos estatais, bem como a prática da descaracterização das casas, como modo de forçar a saída daqueles mais resistentes. Apontei ainda como a instabilidade da posse permite que as agências estatais criem as condições para a realização das remoções, além do mecanismo do endividamento, que faz com que as pessoas continuem enredadas nas malhas do poder mesmo depois de findo o processo de remoção.

A decisão pela intervenção se constituiu a partir da consideração da interrupção ou pela instauração de um novo fluxo. Quando se consideram as transformações urbanas ocorridas desde 2009 no Rio de Janeiro, tendo em vista especialmente a preparação da cidade para as Olimpíadas de 2016, o que se verifica é justamente uma reconfiguração profunda desses fluxos e direções. Áreas inteiras da cidade, como a zona portuária, tiveram seus usos alterados, tanto do ponto de vista das populações que ali habitavam, quanto das atividades de diferentes naturezas (econômicas, políticas) que ali se teciam. O mesmo se deu naquelas regióes ocupadas por favelas, em alguns casos, como a Vila Recreio II, retiradas para abrir caminho para a incorporação imobiliária. Outra cidade, ainda mais segregada e desigual, emergiu dos escombros produzidos pelos tratores da prefeitura, que varreu do mapa casas e vidas, ainda que não sem resistências.

\section{Referências Bibliográficas}

Azevedo, L. \& Faulhaber, L. (2015), SMH 2016: remoção no Rio Olimpico. Rio de Janeiro, Mórula.

BArbosa, Karina Junqueira. (2013), Giorgio Agamben: entre o poder soberano e a biopolitica um diálogo crítico com o pensamento de Carl Schmitt e Michel Foucault. Rio de Janeiro, tese de doutorado, Escola de Serviço Social da Universidade Federal do Rio de Janeiro.

Cardoso, Adauto Lúcio; Mello, Irene de Queiroz \& Jaenisch, Samuel Thomas. (2015), “A implementação do Programa Minha Casa Minha Vida na Região Metropolitana do Rio de Janeiro: agentes, processos e contradições”. In: Amore, Caio Santo, Shimbo, Lúcia Zanin \& Rufino, Maria Beatriz Cruz (orgs.). Minha casa... e a cidade? Avaliação do programa minha casa minha vida em seis estados brasileiros. Rio de Janeiro, Letra Capital, pp. 73-102.

Costa, Pedro D 'Angelo. (2014), O sentido atribuído ao conceito de “interesse público" sob a ótica das disputas de poder na sociedade: um estudo de caso. Rio de Janeiro, monografia, Faculdade Nacional de Direito da Universidade Federal do Rio de Janeiro.

DAs, Veena. (2007), Life and words: violence and the descent into the ordinary. Berkeley, University of California Press. 
Das, Veena \& Poole, Deborah. (2004), Anthropology in the margins of the State. New Delhi, Oxford University Press.

Davies, Frank Andrew. (2017), Deodoro: formas de governo para uma "região olímpica". Rio de Janeiro, tese de doutorado, Instituto de Ciências Sociais da Universidade do Estado do Rio de Janeiro.

FAUlHaber, Lucas. (2013), Rio Maravilha: práticas, projetos políticos e intervenção no território no início do século XXI. Niterói, monografia, Faculdade de Arquitetura e Urbanismo da Universidade Federal Fluminense.

FERNANDES, Adriana. (2013), Escuta ocupação: arte do contornamento, viração e precariedade no Rio de Janeiro. Rio de Janeiro, tese de doutorado, Instituto de Filosofia e Ciências Humanas da Universidade do Estado do Rio de Janeiro.

Foucault, Michel. (2008), Segurança, território, população: curso dado no Collège de France (1978-1979). São Paulo, Martins Fontes.

Freire, Letícia de Luna \& Silva, Mariana T. (2016), “O que está em jogo na cidade olímpica? Conflitos e resistências acerca de remoção de assentamentos populares no Rio de Janeiro". In: Cunha, Neiva Vieira da; Freire, Leticia de Luna; Machado-Martins Maíra \& VeIga, Felipe Berocan (org.). Antropologia do conflito urbano: conexöes Rio-Barcelona. Rio de Janeiro, Lamparina, vol. 1, p. 51-74.

GonçAlves, Rafael Soares. (2015), "Políticas públicas e o retorno das remoções de favelas por ocasião das chuvas de abril de 2010 no Rio de Janeiro". In: KANT DE Lima, Roberto; Mello, Marco Antonio da Silva \& Freire, Letícia de Luna (orgs.). Pensando o Rio:politicas públicas, conflitos urbanos e modos de habitar. Niterói, Intertexto.

Gonçalves, Rafael Soares. (2013), Favelas do Rio de Janeiro: história e direito. Rio de Janeiro, Pallas.

Gros, Frédéric. (2009), Estados de violência: ensaio sobre o fim da guerra. Aparecida, sP, Ideias $\&$ Letras.

Gutterres, Anelise dos Santos. (2014), A resiliência enquanto experiência de dignidade: antropologia das práticas políticas em um cotidiano de lutas e contestaçôes junto a moradoras ameaçadas de remoção nas cidades sede da Copa do Mundo 2014. Porto Alegre, tese de doutorado, Instituto de Filosofia e Ciências Humanas da Universidade Federal do Rio Grande do Sul.

Magalhães, Alexandre. (2017), “Críticas e denúncias: a configuração da ação coletiva contra a remoção de favelas do Rio de Janeiro”. Dados - Revista de Ciências Sociais, 60 (1): 209-238.

MAGAlHães, Alexandre. (2016), “'A remoção foi satanizada, mas não deveria' : o retorno da remoção como forma de intervenção estatal nas favelas do Rio de Janeiro". Dilemas: Revista de Estudos de Conflito e Controle Social, 9 (2): 293-315.

Magalhães, Alexandre. (2013), “O ‘legado’ dos megaeventos esportivos: a reatualização da remoção de favelas no Rio de Janeiro”. Revista Horizontes Antropológicos, 40: 89-118.

Mendes, Alexandre. (2016), "O debate em torno do risco, da moradia e das remoções em um ano de tragédias". In: Mendes, Alexandre \& Cocco, Giuseppe (orgs.). A resistência à 
remoção de favelas no Rio de Janeiro: instituições do comum e resistências urbanas: a história do Núcleo de Terras e Habitação (2007-2011), Rio de Janeiro, Revan, pp. 181-208.

Mendiola, Ignacio. (2017), “De la biopolítica a la necropolítica: la vida expuesta a la muerte”. Eikasia: Revista de Filosofia, 75, maio.

Naback, Clarissa Pires. (2015), Remoçôes biopoliticas: o habitar e a resistência da Vila Autódromo. Rio de Janeiro, dissertação de mestrado, Departamento de Direito da Pontifícia Universidade Católica do Rio de Janeiro.

Petti, Daniela. (2016), "Não tem preço, ninguém esquece sua vida assim": uma etnografia sobre a "luta" contra as remoções de favelas no Rio de Janeiro. Rio de Janeiro, trabalho de conclusão de curso, Escola de Ciências Sociais da Fundação Getúlio Vargas.

Rolnki, Raquel. (2015), Guerra dos lugares: a colonização da terra e da moradia na era das finanças. São Paulo, Boitempo.

Tanaka, Giselle; Sánchez, Fernanda; Monteiro, Poliana; Oliveira, Fabrício Leal (orgs.). (2016), Planejamento e conflitos urbanos: experiências de luta. Rio de Janeiro, Letra Capital, vol. 1.

Telles, Vera. (2010), As cidades nas fronteiras do legal e do ilegal. Belo Horizonte, Argumentum.

\section{Resumo}

A "lógica da intervenção" e a questão da circulação: as remoções de favelas como forma de gerir o espaço urbano no Rio de Janeiro dos Jogos Olímpicos

As remoções de favelas no Rio de Janeiro voltaram à agenda estatal. Desde 2009, aproximadamente 21 mil famílias foram retiradas de seus locais originais de moradia. Neste artigo busco apresentar, com base na descrição etnográfica, duas dimensões interconectadas que estruturam esse processo: a da "lógica da intervenção" e a questão da circulação. Tal empreendimento analítico se apoiará na experiência dos moradores de uma favela da Zona Oeste da cidade, removida entre os anos de 2010 e 2011 em função da construção de uma obra (uma via segregada para ônibus) incluída no rol daquelas que preparariam a cidade para os Jogos Olímpicos de 2016.

Palavras-chave: Favelas; Remoção; Intervenção; Circulação; Jogos Olímpicos. 


\section{Abstract}

The "intervention logic" and the issue of circulation: the removal of slums in order to manage the urban space in Rio de Janeiro of the Olympic Games

The removal of slums in Rio de Janeiro returned to the state agenda. Since 2009, approximately 21,000 families were removed from their original places of residence. In this article I present, from the ethnographic description, two interconnected dimensions that structure this process: the "intervention logic" and the issue of circulation. Such analytic enterprise will rely on the experience of residents of a slum in the West Zone of the city removed between the years 2010 and 2011 due to the construction of a road secreted into buses, work this included in the list of those that would prepare the city for the Olympic Games 2016.

Keywords: Slums; Removal; Intervention; Circulation; Olympic Games.

Texto recebido em 21/2/2018 e aprovado em 23/8/2018.

DOI: 10.11606/0103-2070.ts.2019.143694

Alexandre Magalhães é mestre em sociologia pelo Iuperj, doutor em sociologia pelo Iesp-Uerj, realizou pós-doutorado em antropologia social no Museu Nacional/UfRJ. Atualmente é professor adjunto da Universidade Federal do Rio Grande do Sul (UfRGs).E-mail: alex.socio@ gmail.com. 